\title{
Attitudes and Knowledge of the Harmful Effects of Waterpipe Tobacco Smoking among university students: A study from Jordan
}

\author{
Nour A. Al-Sawalha ${ }^{1}$ - Basima A. Almomani ${ }^{1}$ - Samah F. Al-Shatnawi ${ }^{1}$ - Bashar N. Almomani ${ }^{2}$ \\ Received: 18 September 2020 / Accepted: 7 April 2021 / Published online: 10 April 2021 \\ (C) The Author(s), under exclusive licence to Springer-Verlag GmbH Germany, part of Springer Nature 2021
}

\begin{abstract}
Waterpipe tobacco smoking (WTS) is an emerging behavior worldwide, especially among the youth. It continues to spike in the Middle-Eastern region. WTS is associated with many harmful health-related outcomes.

Objective: Herein, the attitude, knowledge, and factors affecting the knowledge of university students toward the detrimental effects of WTS were examined. This was a cross-sectional study where university students filled an online questionnaire that was available between October 2019 and May 2020. A total of 966 questionnaires were filled. About $40 \%$ of participants were current waterpipe smokers. Around 30\% of participants stated that WTS is not addictive, and about third of them indicated that smoking waterpipe is an essential part of social gathering and is socially accepted behavior. Half of participants (55.8\%) were knowledgeable about the major harmful consequences of WTS. Older students were more knowledgeable as compared to younger ones. In contrast, students from non-medical colleges and waterpipe smokers were less knowledgeable in comparison to those in medical colleges and non-smokers, respectively. More targeted health campaigns to control the use of WTS among university students should be implemented.
\end{abstract}

Keywords Waterpipe tobacco smoke $\cdot$ Knowledge $\cdot$ Attitude $\cdot$ University students $\cdot$ Harmful effects

\section{Introduction}

Waterpipe tobacco smoke (WTS) is an internationally accepted trend of smoking (Maziak et al. 2004). Waterpipe smoking was promoted as a safer alternative to cigarette smoking since it was invented by Hakim AbulFath, an Indian physician. This misconception is due to passing the smoke through the water (Chattopadhyay 2000). The waterpipe apparatus is composed of a head where the flavored tobacco is placed, a metallic body that connects the head to the glass bottle, a glass bottle that is half-filled with water and a hose that connects the bowel with a mouthpiece. The tobacco is placed in the head and is covered

Responsible Editor: Philippe Garrigues

Nour A. Al-Sawalha

nasawalha@just.edu.jo

1 Department of Clinical Pharmacy, Faculty of Pharmacy, Jordan University of Science and Technology, P.O. Box 3030, Irbid 22110 , Jordan

2 Ministry of Health, National Institute of Forensic Medicine, Amman, Jordan with perforated aluminum foil where the heated charcoal is placed (Akl et al. 2011; Gatrad et al. 2007).

Worldwide, in 2007, around 100 million individuals smoked waterpipe on daily basis (Gatrad et al. 2007). The popularity of waterpipe smoking has increased dramatically in several countries, especially among youth population, and it even replaced cigarette smoking as a popular form of tobacco consumption (Akl et al. 2011). The prevalence of waterpipe smoking among youth is excessively high in European and Middle-Eastern countries, and it is the highest among adults in the Middle-Eastern countries (Jawad et al. 2018).

The rate of waterpipe smoking has increased in several countries. Soulakova and colleagues reported an increased rate of current WTS use (from 1 to $2 \%$ ) and ever-used (from 7 to $12 \%$ ) among 55,352 young adults (18-30 years old) in the USA during the period from 2010-2011 to 2014-2015 (Soulakova et al. 2018). Further, the prevalence of WTS was $4.8 \%$ among international medical students in Germany and Hungary (Balogh et al. 2018). In Lebanon, the overall prevalence of WTS among university students was $21.1 \%$ and $11.3 \%$ for those who smoked both cigarettes and waterpipe (Tamim et al. 2003). In Jordan, $61.1 \%$ of male university students had ever consumed WTS while $42.7 \%$ used WTS 
at least monthly (Azab et al. 2010). In addition, it has been found that $53 \%$ of females university students from Jordan preferred WTS (Dar-Odeh et al. 2010). The prevalence of WTS among Jordanian women has increased drastically in the 21 st century (Jawad et al. 2016). The prevalence was $4.1 \%$ in 2002 and reached $10.2 \%$ in 2012 (Jawad et al. 2016), and prevalence of women who smoked WTS was almost as high as cigarette smoking (10.2\% vs. $10.9 \%)$ (Jawad et al. 2016).

Waterpipe tobacco smoking results in several detrimental health effects. Waterpipe tobacco smoke exposure increases the risk of developing cardiovascular diseases such as increased blood pressure and risk of coronary artery disease (Bhatnagar et al. 2019). Further, it increases the risk of developing diabetes and metabolic syndrome (Saffar Soflaei et al. 2018), respiratory diseases (El-Zaatari et al. 2015), male infertility Fawzy (2011), cognitive deficit (Meo et al. 2017), and cancer (Montazeri et al. 2017). Moreover, several studies showed that WTS exposure during pregnancy affects the offspring negatively. Prenatal waterpipe tobacco smoke is associated with low birth weight (Abusalah et al. 2012; Bachir and Chaaya 2008; Bener et al. 2012; Rachidi et al. 2013; Tamim et al. 2008), infant mortality (Singh et al. 2013), as well as pulmonary complications at birth (Rachidi et al. 2013). Given the strikingly large incremental rate of WTS in some countries including Jordan, it is important to understand the factors that might have led the expansion in this behavior.

Previous studies have examined the knowledge and attitude of university students to WTS. It has been shown that waterpipe smoking among university students in Jordan was associated with upper middle income level as well as male gender (Azab et al. 2010). A cross-sectional study that was conducted in five Mediterranean countries revealed that most university students had misperceptions of waterpipe harm (Abu-Rmeileh et al. 2018). Such findings highlight the needs to increase the awareness of university students about the harmful effects of WTS. Though university students realized that WTS cessation prevented the harmful effects, they continued waterpipe smoking to not lose their social life with friends and eliminate the pleasure effects of reduced anxiety and fatigue (Khani Jeihooni et al. 2018). In the light of increased scientific evidence about the consequences of waterpipe smoking, there is a need to examine the attitude, knowledge, and factors affecting the knowledge of university students toward the harmful effects of WTS.

\section{Subjects and methods}

\section{Study population and design}

This was a cross-sectional questionnaire based observational study. University students $(n=966)$ who were attending public and private universities in North, Middle, and South Jordan were invited to participate in the study and filled the online questionnaire. The online questionnaire was available from October 2019 till May 2020. The questionnaire was developed based on the literature (Abu-Rmeileh et al. 2018; AlQahtani 2017; Arshad et al. 2019; Awan et al. 2016) and discussion within the research team. The questionnaire was tested for face validity by experts in the field, and it was piloted $(n=20)$ to improve the clarity of the questions. The questionnaire was developed in English then it was translated to Arabic.

The questionnaire contains four main sections; demographics, smoking habits, attitude, and knowledge sections. The questionnaire includes closed-ended questions. The attitude section is composed of 5 items with 5-point Likert scale ("strongly agree" to "strongly disagree"). Cronbach's $\alpha$ (alpha) of attitude section was 0.72 which indicated a good reliability. The knowledge section composed of 12 items with 3 answer options (true, false, do not know). The approximate time to complete the questionnaire was $10-15 \mathrm{~min}$.

\section{Statistical analysis}

Categorical variables were presented as numbers and percent, and the continuous variables were presented as median (interquartile range). The univariate analysis was performed using Mann-Whitney $U$ test for continuous variables and chi-square test for categorical variables as appropriate. The answers to different knowledge questions were calculated as categorical variables using a cutoff point for total scores. Participants who answered $\geq 7$ questions were categorized as knowledgeable while those who answered $<7$ questions were categorized as non-knowledgeable. Binary logistic regression analysis was used to determine factors that are independently associated with participants' knowledge. All participants who answered "do not know" were considered "incorrect." For the purpose of analysis in attitude section, both answer options "agree" and "strongly agree" were combined as one category and both "disagree" and "strongly disagree" as one category. $p$-value $\leq$ 0.05 was considered statistically significant. The analysis was performed utilizing Statistical Package for Social Sciences (SPSS Inc., Chicago, IL) version 20.

\section{Results}

\section{Demographic data of participants}

A total of 966 students participated in the current study. Most participants were females $(67 \%)$ and studied in governmental universities (88\%). More than half of participants (59\%) were enrolled in medical college and were in their first and second year of college $(\sim 50 \%)$. Almost half of participants $(\sim 50 \%)$ 
lived in Middle Jordan. Less than half of participants (45\%) received less than 100 Jordanian Dinar (JD) as a pocket money per month (Table 1).

\section{Smoking habits of participated students}

Only $16.6 \%$ of participants were current cigarette smokers, while $40.5 \%$ of them were waterpipe smokers. A quarter of waterpipe smokers $(26.9 \%)$ smoked it daily, and $\sim 65 \%$ of them spent 30-90 min in each smoking session. About half of participants (49\%) smoked waterpipe in the house, and $\sim 41 \%$ of them tried it for the first time for curiosity purposes (Table 2).

\section{Attitude of participated students toward waterpipe smoking}

About $16 \%$ and $\sim 29 \%$ of participants agreed that smoking waterpipe is less dangerous and not addictive as compared

Table 1 Demographics and characteristics of participants
Table 2 Smoking habits of participants

Characteristics $^{\mathrm{a}}$

All participants ${ }^{\mathrm{b}}$ $n=966$

Current cigarette smokers

- No

$796(83.4)$

- Yes

$159(16.6)$

Current waterpipe smoker

- No

$574(59.5)$

- Yes

$391(40.5)$

Frequency of waterpipe smoking

- Daily

105 (26.9)

-1-2 times per week

$124(31.8)$

-1-2 times per month

$161(41.3)$

Duration of each waterpipe smoking session

- Less than $30 \mathrm{~min}$

-30-90 min

109 (28)

->90 min

$252(64.8)$

28 (7.2)

Place of waterpipe smoking

- House

191 (49)

- Friend's house

$42(10.8)$

- Relatives' house

$19(4.9)$

- Public place (cafés/restaurants)

$138(35.4)$

Reason behind waterpipe smoking for the first time

- Curiosity

$158(40.5)$

- Seeking for pleasure

$133(34.1)$

- Forming relationships with colleagues

$11(2.8)$

- Becoming free from community constraints

$8(2.1)$

- Others

$80(20.5)$

${ }^{\mathrm{a}}$ All data expressed as $\mathrm{n}(\%)$ of participants

${ }^{\mathrm{b}}$ Values were calculated based on the number of students who responded to the correspondent question

to cigarette smoking respectively. In addition, about third of participants indicated that smoking waterpipe is an essential part of social gathering and is socially accepted behavior. However, only $18 \%$ of them considered it as a mental stimulant (Fig. 1).

\section{Knowledge of participated students}

Most participants ( $71 \%$ ) stated that waterpipe is composed of natural products, and more than half of them $(55 \%)$ had the misconception that, as smoke passes the water, harmful substances are filtered. However, only $27 \%$ of participants knew that a 1-h waterpipe smoking session involves 200 puffs compared to 20 puffs for cigarette smoking.

The majority of participants $(>80 \%)$ knew that waterpipe smoking increases the risk of developing cardiovascular and respiratory diseases as well as developing cancer. However, less than half of them knew that waterpipe smoking negatively affects the cognition and increased risk of developing metabolic syndrome and diabetes. Further, less than third of participants $(\sim 24 \%)$ knew that waterpipe tobacco smoke exposure increases the risk of male infertility. 
Fig. 1 Attitude of participants toward waterpipe smoking. Values were calculated based on the number of students who responded to the correspondent question

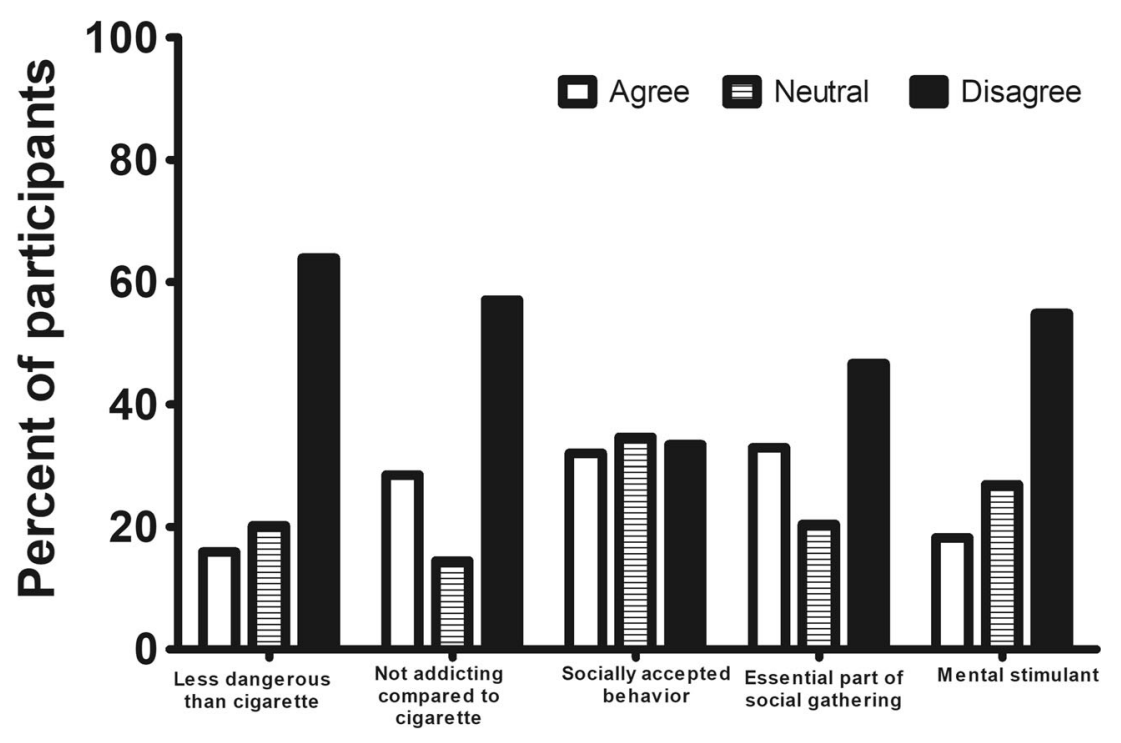

Approximately $63 \%$ of participants knew that waterpipe smoking during pregnancy increases the risk of pulmonary complication at birth. However, less than half of them knew the harmful effects of waterpipe smoking during pregnancy on low birth weight as well as the increased infant mortality. Table 3 summarizes the correct responses to knowledge questions.

\section{Factors affecting knowledge of participated students}

More than half of university students were knowledgeable about the harmful consequences of WTS $(55.8 \%, n=539)$. The results of multivariate analysis of factors affecting students' knowledge are presented in Table 4. Older students were more knowledgeable than younger ones $(\mathrm{OR}=1.194$,
95\% CI 1.087-1.311, $p$ value < 0.001). On the other hand, students from non-medical college were less knowledgeable than those in medical college $(\mathrm{OR}=0.575,95 \%$ CI 0.430 $0.769, p$ value $<0.001)$. In addition, waterpipe smokers were less knowledgeable than non-smokers $(\mathrm{OR}=0.554,95 \% \mathrm{CI}$ $0.413-0.742, p$ value $<0.001)$.

\section{Discussion}

Given the alarmingly high rates of waterpipe smoking among youth in Jordan, this research was conducted to examine the attitude and knowledge of university students about the harmful effects of WTS.
Table 3 Overview of participants' knowledge

\begin{tabular}{ll}
\hline Knowledge items & $\begin{array}{l}\text { Correct } \\
\text { answer } \\
n(\%)\end{array}$ \\
\hline Waterpipe is composed of natural products & $679(70.7)$ \\
The water filters the harmful substances that are present in waterpipe & $531(55)$ \\
A 1-h waterpipe smoking session involves 200 puffs compared to 20 puffs for cigarette smoking & $259(26.9)$ \\
Waterpipe tobacco smoke exposure increases the risk of developing cardiovascular diseases as & $834(86.7)$ \\
increased blood pressure and coronary artery disease & $853(88.6)$ \\
Waterpipe tobacco smoke exposure increases the risk of respiratory diseases as chronic & \\
bronchitis & $836(86.9)$ \\
Waterpipe tobacco smoke exposure increases the risk of cancer as lung cancer and esophageal & \\
$\quad$ cancer & $436(45.3)$ \\
$\quad$ memory & $379(39.4)$ \\
Waterpipe tobacco smoke exposure increases the risk of diabetes and metabolic syndrome & $227(23.5)$ \\
Waterpipe tobacco smoke exposure increases the risk of infertility in males & $609(63.2)$ \\
Prenatal waterpipe tobacco smoke is associated with pulmonary complications at birth & $461(47.9)$ \\
Prenatal waterpipe tobacco smoke is associated with low birth weight & $449(46.7)$ \\
Prenatal waterpipe tobacco smoke is associated with infant mortality &
\end{tabular}


Table 4 Multivariate analysis of factors affecting participants' knowledge

\begin{tabular}{|c|c|c|}
\hline Factors $^{\mathrm{a}}$ & OR $(95 \% \mathrm{CI})$ & $p$ value \\
\hline $\mathrm{Age}^{\mathrm{b}}$ & $1.194(1.087-1.311)$ & $<0.001$ \\
\hline \multicolumn{3}{|l|}{ Gender } \\
\hline $\begin{array}{l}\text { - Female } \\
\text { - Male }\end{array}$ & $\begin{array}{l}\text { Ref } \\
0.804(0.582-1.111)\end{array}$ & 0.186 \\
\hline \multicolumn{3}{|l|}{ College } \\
\hline $\begin{array}{l}\text { - Medical } \\
\text { - Not medical } \\
\text { Year of study }\end{array}$ & $\begin{array}{l}\text { Ref } \\
0.575(0.430-0.769)\end{array}$ & $<0.001$ \\
\hline $\begin{array}{l}\text { - } 1 \text { st and } 2 \text { nd } \\
\text { - 3rd and 4th } \\
\text { - 5th and 6th }\end{array}$ & $\begin{array}{l}\text { Ref } \\
0.764(0.548-1.065) \\
1.089(0.587-2.021)\end{array}$ & $\begin{array}{l}0.155 \\
0.112 \\
0.787\end{array}$ \\
\hline \multicolumn{3}{|c|}{ Pocket money spent monthly } \\
\hline $\begin{array}{l}\cdot<100 \mathrm{JD} \\
\cdot 100-300 \mathrm{JD} \\
\cdot>300 \mathrm{JD}\end{array}$ & $\begin{array}{l}\text { Ref } \\
1.299(0.956-1.765) \\
1.145(0.758-1.730)\end{array}$ & $\begin{array}{l}0.246 \\
0.094 \\
0.519\end{array}$ \\
\hline \multicolumn{3}{|c|}{ Current waterpipe smoker } \\
\hline $\begin{array}{l}\cdot \text { No } \\
\text { - Yes } \\
\text { Current cigarett }\end{array}$ & $\begin{array}{l}\text { Ref } \\
0.554(0.413-0.742)\end{array}$ & $<0.001$ \\
\hline $\begin{array}{l}\cdot \text { No } \\
\text { - Yes }\end{array}$ & $\begin{array}{l}\text { Ref } \\
1.056(0.701-1.590)\end{array}$ & 0.794 \\
\hline
\end{tabular}

${ }^{\text {a }}$ All data expressed as $n(\%)$ of participants unless otherwise indicated

${ }^{\mathrm{b}}$ Data described as median (IQR)

About $40 \%$ of enrolled participants indicated current waterpipe smoking compared to $\sim 17 \%$ who were cigarette smokers. This highlights the shift in popularity from cigarette smoking to waterpipe smoking among university students of Jordan, consistent with university students in USA (Barnett et al. 2013). The rate of waterpipe smoking is considered high as compared to previously reported overall rates of smoking from international, national, and local studies in the MiddleEastern region. A previous study in Jordan revealed that the prevalence of waterpipe smoking was $\sim 19 \%$ among adult males and $\sim 23 \%$ among adult females (Abu-Helalah et al. 2015). In addition, the prevalence rate among Arab youth varies (13-15 years old) in different countries; for example, it was $0.9 \%$ in Oman, $19 \%$ in Jordan, $7 \%$ in Egypt, and $\sim 34 \%$ in Lebanon (Kheirallah et al. 2016). The higher prevalence in the current study can be explained by the difference in age groups, as focused on university students. Furthermore, it has been reported that $8.4 \%$ of the surveyed college and university students in USA were current waterpipe smokers (Primack et al. 2012). This highlights the alarming increased popularity and acceptance of WTS among university students in Jordan.

Nearly $27 \%$ of waterpipe smokers in this research smoked it on daily basis, and $65 \%$ of them spent $30-90 \mathrm{~min}$ in each WTS session. Even though female gender was majority in this study, smoking rates were significantly high, and no significant difference was found between rates reported by females vs. males. Such findings confirm the continuous increments in WTS habits (Abu-Helalah et al. 2015) among young age females in Jordan (Abu-Helalah et al. 2015). Attitudes of WTS in youthful communities (e.g., colleges and universities) in Jordan might have resulted in such transition in WTS behaviors across genders (Taylor et al. 1998).

In the current study, around $16 \%$ and $29 \%$ of students perceived WTS in comparison to cigarette smoking, as being safer on health and not addictive behavior, respectively. This rate is lower than rates reported in other studies (Arshad et al. 2019; Jawaid et al. 2008), which reflects better knowledge about the harmful effects of WTS among study participants. It has been shown that the general perception among university students was that WTS is less harmful and addictive and is socially acceptable as an alternative to cigarette smoking (Arshad et al. 2019). Noteworthy, participating university students in this study considered WTS behavior as not only being socially accepted but also as an essential part of their social gathering activities. In concordance to regional findings, such attitudes might have contributed to the current emerging public health problem of WTS behavior among youth generations (Abu-Helalah et al. 2015; Azab et al. 2010). The overall acceptability of WTS behavior might have been gained because of the growing popularity of such behavior across genders in Jordan; Waterpipe is part of the menu in almost all restaurants in Jordan. As reported by $35.4 \%$ of waterpipe smokers, public places are the main places for WTS in this study. Therefore, low prices and accessibility to widespread waterpipe cafés might be considered influential factors to the reported attitudes WHO (n.d.). Regarding local distribution of waterpipe cafés in Jordan (on Google maps), anyone can easily notice the high density of these shops in locations nearby college campuses and student dormitories. Insufficient regulations that control licenses offered by the Jordanian government to cafés and restaurants that serve waterpipe might have supported the overall acceptability of WTS behaviors (Samet et al. 2001).

Concerning their knowledge about harmful effects of WTS, a large proportion of study participants $(55.8 \%)$ were knowledgeable about these effects. Whereas, results from previous international studies have indicated poor knowledge about WTS harms among current waterpipe smoking university students (Alqahtani et al. 2019; Arshad et al. 2019; Awan et al. 2016; Jawaid et al. 2008). About $15 \%$ of university students at medical fields in Saudi Arabia failed to recognize a single harmful effect of WTS (Awan et al. 2016). Worldwide, and similar to current findings, students were generally able to identify cardiovascular, respiratory, and cancer-related harmful consequences of WTS (Arshad et al. 2019). However, more than half of study participants were not able to identify the negative consequences of WTS that are related to mental and cognitive effects as well as productivity, 
pregnancy, and neonatal related harms. This might be due to unavailability of comprehensive information about harmful consequences that are related to WTS. Similar to previous research findings (Arshad et al. 2019), in comparison to non-waterpipe smokers, and as predicted, current smokers were less knowledgeable about negative harms. Thus, more comprehensive rather than general knowledge of health threats related to WTS might influence the current status of WTS among university students. Unsurprisingly, older students and those who are medically oriented were more knowledgeable about harmful effects of WTS as compared to their counterparts. Maturation and medical information from the field of study might improve knowledge level of WTS harms. However, a very recent systematic review that has explored attitudes and knowledge about WTS among university students concluded that knowledge about the general hazards of WTS might not deter the behavior of WTS (Arshad et al. 2019). Thus, prevention programs (targeting public population and/or university students) that aim to control WTS should not focus on increasing knowledge and awareness of harmful consequences only. Rather, programs should be multifaceted by integrating aspects of policy, religious, and family-related perceptions, beside educating students about adverse effects of WTS to effectively interfere with such complex behaviors. This highlights the needs for more organized governmental efforts in developing general and universitybased policies that target waterpipe smoking among youth and adults.

The current study has several limitations. First, it utilized an online questionnaire where there is a risk of sample selection bias. However, current university students are very familiar and frequently visiting many different online portals Kunsoon Park et al. (2019); thus, such method seems practical and feasible (saving time and costs of conventional data collection and enhancing the generalizability of study findings) as it might have facilitated responses from different geographical regions in Jordan, especially during COVID-19 pandemic (Lefever et al. 2007). Therefore, the presented data might reflect the general attitude and knowledge of the targeted population of university students. Second, this study is crosssectional; thus, documented findings may not reflect the actual temporal effects of knowledge advancement on the actual behaviors of WTS. Third, the current study did not assess dual use of both cigarettes and waterpipe and did not differentiate between attitudes among smokers and ex-smokers. Fourth, the translated Arabic version of the questionnaire has not been validated.

In conclusion, the university students in Jordan report extensive use of WTS. Both genders highlight the general acceptance of WTS behavior as a core activity during their social gathering. They have indicated wrong perceptions about WTS, as being less harmful and non-addictive when compared to cigarette smoking. More targeted university-based health campaigns should be implemented to control the use of WTS among students. Application of interventional efforts that curb WTS among university students in particular might be through different modes including online approaches such as emails and social media.

Acknowledgements The authors thank all students who participated in the study.

Author contribution NAS conceptualized the work, developed the questionnaire, collected the data, and assisted in data analysis and writing the manuscript. BAM developed the questionnaire, collected the data, analyzed the data, and revised of the manuscript. SFS assisted in data analysis and wrote the manuscript. BNA assisted in data collection and revised the manuscript. All authors read and approved the final manuscript.

Funding This work was supported by Deanship of Scientific Research at Jordan University of Science and Technology (grant number 20190527).

Data availability All data generated or analyzed during this study are included in this published article.

\section{Declarations}

Ethics approval and consent to participate This study was approved by the institutional review board (IRB) at Jordan University of Science and Technology (JUST) before conducting the study (reference number 13/ 126/2019).

Consent for publication Not applicable

Conflict of interest The authors declare no competing interests.

\section{References}

Abu-Helalah MA, Alshraideh HA, Al-Serhan AA, Nesheiwat AI, Da'na M, Al-Nawafleh A (2015) Epidemiology, attitudes and perceptions toward cigarettes and hookah smoking amongst adults in Jordan. Environ Health Prev Med 20:422-433

Abu-Rmeileh NME, Alkhuffash O, Kheirallah K, Mostafa A, Darawad M, Al-Farsi Y, Yusufali A, Thomas J, Salama M, Hamadeh RR, Nakkash R, Salloum RG (2018) Harm perceptions of waterpipe tobacco smoking among university students in five Eastern Mediterranean Region countries: a cross-sectional study. Tob Induc Dis 16

Abusalah A, Gavana M, Haidich AB, Smyrnakis E, Papadakis N, Papanikolaou A, Benos A (2012) Low birth weight and prenatal exposure to indoor pollution from tobacco smoke and wood fuel smoke: a matched case-control study in Gaza Strip. Matern Child Health J 16:1718-1727

Akl EA, Gunukula SK, Aleem S, Obeid R, Jaoude PA, Honeine R, Irani J (2011) The prevalence of waterpipe tobacco smoking among the general and specific populations: a systematic review. BMC Public Health 11:244

AlQahtani J (2017) Knowledge, attitude and practice of tobacco smoking among health colleges' students at Najran University, Saudi Arabia: a cross-sectional descriptive study. Journal of Health Specialties 5: $35-41$ 
Alqahtani MM, Goodfellow LT, Zimmerman RD, Zavorsky GS (2019) Waterpipe smoking in health-care students: prevalence, knowledge, attitudes, and motives. Respir Care 64:321-327

Arshad A, Matharoo J, Arshad E, Sadhra SS, Norton-Wangford R, Jawad M (2019) Knowledge, attitudes, and perceptions towards waterpipe tobacco smoking amongst college or university students: a systematic review. BMC Public Health 19:439

Awan KH, Alrshedan A, Al Kahtani M, Patil S (2016) Waterpipe smoking among health sciences university students: knowledge, attitude and patterns of use. Saudi Dent J 28:189-193

Azab M, Khabour OF, Alkaraki AK, Eissenberg T, Alzoubi KH, Primack BA (2010) Water pipe tobacco smoking among university students in Jordan. Nicotine Tob Res 12:606-612

Bachir R, Chaaya M (2008) Maternal smoking: determinants and associated morbidity in two areas in Lebanon. Matern Child Health J 12: 298-307

Balogh E, Faubl N, Riemenschneider H, Balazs P, Bergmann A, Cseh K, Horvath F, Schelling J, Terebessy A, Wagner Z, Voigt K, Fuzesi Z, Kiss I (2018) Cigarette, waterpipe and e-cigarette use among an international sample of medical students. Cross-sectional multicenter study in Germany and Hungary. BMC Public Health 18:0185494

Barnett TE, Smith T, He Y, Soule EK, Curbow BA, Tomar SL, McCarty C (2013) Evidence of emerging hookah use among university students: a cross-sectional comparison between hookah and cigarette use. BMC Public Health 13:302

Bener A, Salameh KM, Yousafzai MT, Saleh NM (2012) Pattern of maternal complications and low birth weight: associated risk factors among highly endogamous women. ISRN obstetrics and gynecology 2012:540495

Bhatnagar A, Maziak W, Eissenberg T, Ward KD, Thurston G, King BA, Sutfin EL, Cobb CO, Griffiths M, Goldstein LB, Rezk-Hanna M (2019) Water pipe (Hookah) smoking and cardiovascular disease risk: a scientific statement from the American Heart Association. Circulation 139:e917-e936

Chattopadhyay A (2000) Emperor Akbar as a healer and his eminent physicians. Bulletin of the Indian Institute of History of Medicine 30:151-157

Dar-Odeh NS, Bakri FG, Al-Omiri MK, Al-Mashni HM, Eimar HA, Khraisat AS, Abu-Hammad SM, Dudeen A-AF, Abdallah MN, Alkilani SM, Al-Shami L, Abu-Hammad OA (2010) Narghile (water pipe) smoking among university students in Jordan: prevalence, pattern and beliefs. Harm Reduct J 7:10

El-Zaatari ZM, Chami HA, Zaatari GS (2015) Health effects associated with waterpipe smoking. Tob Control 24:i31-i43

Fawzy IA (2011) NNKaAMA, 2011 Reproductive toxicity of tobacco Shisha smoking on semen parameters and hormones levels among adult Egyptian men. Research Journal of Environmental Toxicology 5:282-292

Gatrad R, Gatrad A, Sheikh A (2007) Hookah smoking. BMJ (Clinical research ed) 335:20

Jawad M, Abdulrahim S, Daouk A (2016) The social patterning of tobacco use among women in Jordan: the protective effect of education on cigarette smoking and the deleterious effect of wealth on cigarette and waterpipe smoking. Nicotine \& tobacco research : official journal of the Society for Research on Nicotine and Tobacco 18:379-385

Jawad M, Charide R, Waziry R, Darzi A, Ballout RA, Akl EA (2018) The prevalence and trends of waterpipe tobacco smoking: a systematic review. PLoS One 13:e0192191

Jawaid A, Zafar AM, Rehman TU, Nazir MR, Ghafoor ZA, Afzal O, Khan JA (2008) Knowledge, attitudes and practice of university students regarding waterpipe smoking in Pakistan. Int $\mathrm{J}$ Tuberc Lung Dis 12:1077-1084

Khani Jeihooni A, Khiyali Z, Kashfi SM, Kashfi SH, Zakeri M, Amirkhani M (2018) Knowledge and attitudes of university students towards hookah smoking in Fasa, Iran. Iran J Psychiatry Behav Sci 12:e11676

Kheirallah KA, Alsulaiman JW, Mohammad HA, Alzyoud S, Veeranki SP, Ward KD (2016) Waterpipe tobacco smoking among Arab Youth; a cross-country study. Ethn Dis 26:107-112

Kunsoon Park NP, Heo W, Gustafson K (2019) What prompts college students to participate in online surveys? Int Educ Stud 12:10

Lefever S, Dal M, Matthíasdóttir Á (2007) Online data collection in academic research: advantages and limitations. Br J Educ Technol 38:574-582

Maziak W, Ward KD, Afifi Soweid RA, Eissenberg T (2004) Tobacco smoking using a waterpipe: a re-emerging strain in a global epidemic. Tob Control 13:327-333

Meo SA, Bashir S, Almubarak Z, Alsubaie Y, Almutawa H (2017) Shisha smoking: impact on cognitive functions impairments in healthy adults. Eur Rev Med Pharmacol Sci 21:5217-5222

Montazeri Z, Nyiraneza C, El-Katerji H, Little J (2017) Waterpipe smoking and cancer: systematic review and meta-analysis. Tob Control 26:92-97

Primack BA, Shensa A, Kim KH, Carroll MV, Hoban MT, Leino EV, Eissenberg T, Dachille KH, Fine MJ (2012) Waterpipe smoking among U.S. university students. Nicotine Tob Res 15:29-35

Rachidi S, Awada S, Al-Hajje A, Bawab W, Zein S, Saleh N, Salameh P (2013) Risky substance exposure during pregnancy: a pilot study from Lebanese mothers. Drug, healthcare and patient safety 5:123131

Saffar Soflaei S, Darroudi S, Tayefi M, Nosrati Tirkani A, Moohebati M, Ebrahimi M, Esmaily H, Parizadeh SMR, Heidari-Bakavoli AR, Ferns GA, Ghayour-Mobarhan M (2018) Hookah smoking is strongly associated with diabetes mellitus, metabolic syndrome and obesity: a population-based study. Diabetol Metab Syndr 10: 018-0335

Samet JM, Yoon S-Y, Initiative WTF (2001) Women and the tobacco epidemic: challenges for the 21 st century. Organization, World Health

Singh PN, Eng C, Yel D, Kheam T, Job JS, Kanal K (2013) Maternal use of cigarettes, pipes, and smokeless tobacco associated with higher infant mortality rates in Cambodia. Asia Pac J Public Health 25: $64 \mathrm{~S}-74 \mathrm{~S}$

Soulakova JN, Pham T, Owens VL, Crockett LJ (2018) Prevalence and factors associated with use of hookah tobacco among young adults in the U.S. Addict Behav 85:21-25

Tamim H, Terro A, Kassem H, Ghazi A, Khamis TA, Hay MM, Musharrafieh U (2003) Tobacco use by university students, Lebanon, 2001. Addiction 98:933-939

Tamim H, Yunis KA, Chemaitelly H, Alameh M, Nassar AH, National Collaborative Perinatal Neonatal Network Beirut L (2008) Effect of narghile and cigarette smoking on newborn birthweight. BJOG 115: 91-97

Taylor SM, Ross NA, Goldsmith CH, Zanna MP, Lock M, Group CR (1998) Measuring attitudes towards smoking in the Community Intervention Trial for Smoking Cessation (COMMIT). Health Educ Res 13:123-132

WHO (n.d.) WHO Tobacco

Publisher's note Springer Nature remains neutral with regard to jurisdictional claims in published maps and institutional affiliations. 